\title{
Condições higiênico sanitárias de Unidades de Alimentação e Nutrição de escolas públicas do estado do Tocantins
}

\section{Lisandra Lustoza Ferro', Claudia Jaqueline Fialho², Caroline Roberta Freitas Pires ${ }^{2}$, Natália de Barros Teles ${ }^{1}$, Viviane Ferreira dos Santos ${ }^{1}$}

Este trabalho visou avaliar condições higiênico sanitárias das Unidades de Alimentação e Nutrição de 35 escolas públicas do estado do Tocantins, de 12 municípios selecionados pelo FNDE, monitoradas pelo Centro Colaborador em Alimentação e Nutrição da Universidade Federal do Tocantins (CECANE/UFT). Utilizou-se um formulário semiestruturado para avaliar as Unidades de Alimentação e Nutrição Escolares, com perguntas acerca dos manipuladores, edifícios e instalações da área de preparo de alimentos, equipamentos e utensílios, higienização ambiental e saneamento, área de armazenamento, controle de qualidade e controle de estoque. A coleta de dados foi realizada entre os meses de maio a dezembro de 2016 e os dados obtidos a partir do checklist foram transformados em percentuais. Foram indicadas as principais não conformidades em relações às legislações vigentes (como resolução 216/2004 e Lei 11.947/2009). Dentre os resultados encontrados destaca-se incongruidades acerca dos manipuladores de alimentos, área de preparo dos alimentos, equipamentos e utensílios, higienização ambiental e saneamento, armazenamento dos alimentos, controle de qualidade e controle de estoque. Concluiu-se que há a necessidade de capacitação permanente dos manipuladores e intervenções de gestores, para garantir as condições higiênico sanitárias das unidades escolares públicas do estado do Tocantins e propiciar a oferta da alimentação segura.

Palavras-chave: Alimentação escolar. Unidades de alimentação e nutrição. Condições higiênico sanitárias.

\section{Hygienic sanitary conditions of Food and Nutrition Units of public schools in the state of Tocantins}

This work aimed to evaluate the sanitary conditions of the Food and Nutrition Units of 35 public schools in the state of Tocantins, from 12 municipalities selected by the FNDE, monitored by the Collaborating Center on Food and Nutrition of the Federal University of Tocantins (CECANE/UFT). A semi-structured form was used to evaluate the School Nutrition and Nutrition Units, with questions about the manipulators, buildings and facilities of the area of preparation of food, equipment and utensils, environmental sanitation and sanitation, storage area, quality control and inventory control. Data collection was performed between May and December 2016 and data obtained from the Checklist were transformed into percentages. The main unconformities in relation to the current legislation (like resolution 216/2004 and Law 11.947 / 2009) were indicated. Among the results found are incongruities about food handlers, food preparation area, equipment and utensils, environmental sanitation and sanitation, food storage, quality control and inventory control. It was concluded that there is a need for

1 Acadêmica do curso de Nutrição - Universidade Federal do Tocantins.

2 Docente do curso de Nutrição - Universidade Federal do Tocantins. Endereço para correspondência: Quadra 109 Norte, Avenida NS15, ALCNO-14 - Plano Diretor Norte, CEP: 77001-090, Palmas - TO, Tel.: (63) 32328323.E-mail: cecane.to@mail.uft.edu.br 
permanent training of the manipulators and interventions of managers, to guarantee hygienic sanitary conditions of public school units in the state of Tocantins and to provide safe food supply.

Keywords: School feeding. Food and nutrition units. Hygienic sanitary conditions.

\section{INTRODUÇÃO}

A oferta de alimentos seguros e saudáveis é responsabilidade do Estado fundamentada pelo Direito Humano à Alimentação Adequada (DHAA) e preceito da Segurança Alimentar e Nutricional (SAN), em combate à fome e desnutrição ${ }^{[1]}$. Para a oferta desses alimentos foram criados projetos, como o Programa Nacional de Alimentação Escolar (PNAE), que se destaca como o programa mais antigo do país e de atendimento universal dos alunos das escolas de educação básica pública e filantrópicas ${ }^{[2]}$.

Entre as premissas do PNAE destacase a promoção da saúde e alimentação adequada e saudável, que visa "contribuir para o crescimento do aluno nas áreas social, cognitiva, emocional e principalmente, nutricional"[2], de forma que é imprescindível para a promoção da saúde a oferta de alimentos em condições higiênicas conforme previstas na legislação brasileira, preconizada na Resolução da Diretoria Colegiada (RDC) 216/2004 e RDC $275 / 2002^{[3,4]}$.

A Resolução 216 criada no ano de 2004 pela Agência Nacional de Vigilância Sanitária (ANVISA) traz os procedimentos de boas práticas, que norteiam a construção, a higienização de equipamentos, a manipulação e a distribuição das refeições das Unidades de Nutrição e Alimentação (UAN), os quais devem ser aplicados a fim de garantir a seguridade dos alimentos ${ }^{[5,6]}$.

Ressalva-se a importância da RDC 216/2004 ao abordar os requisitos a serem cumpridos pelos manipuladores de alimentos, como o uso de uniformes e equipamentos que garantem a segurança durante o trabalho; realização de exames médicos, o que assegura que não ocorrerá a transmissão de doenças infecto - contagiosas por meio dos alimentos; o não uso de adornos como medida de proteção para diminuir as possibilidades de contaminação e/ou acidentes durante o processo de manipulação ${ }^{[3]}$.

Enquanto que a RDC 275/2002 destaca-se por trazer a lista de verificação das Boas Práticas de Fabricação aplicável às indústrias alimentícias e locais de produção de alimentos, avaliando desde às edificações (internas e externas), iluminação, ventilação, controle de vetores e pragas, abastecimento de água, higiene ambiental e saneamento, equipamentos e utensílios, manipuladores, produção, armazenamento, controle de qualidade do produto final, documentação, dentre outros quesitos ${ }^{[4]}$.

Diante do fato da lista de verificação da RDC 275/2002 se direcionar para UAN industriais e devido as características semelhantes das UAN escolares e domésticas surge a necessidade de elaboração de formulários que abordem sobre os critérios e parâmetros dos alimentos, verificação das condições sanitárias e das práticas da produção alimentícia realizadas nas escolas ${ }^{[7]}$.

A inevitabilidade da realização de avaliações dos padrões das UAN escolares no Brasil deve-se pela magnitude dos problemas que podem ser gerados pela falta de higiene no preparo dos alimentos. Como exemplo das complicações do mau funcionamento das unidades destaca-se as doenças transmitidas por alimentos (DTA), responsável por 2 milhões de 
mortes por ano ${ }^{[8]}$, além de que a produção de alimentos não seguros contradiz os objetivos da alimentação escolar.

Para a garantia da boa execução do PNAE, em 2006 foi estabelecido parceria entre o Fundo Nacional de Desenvolvimento da Educação (FNDE) e Instituições de Ensino Superior para gerar os Centros de Colaboradores de Alimentação e Nutrição Escolar (CECANE) ${ }^{[2]}$, que tencionam a capacitação dos atores sociais envolvidos com o programa, bem como assessoria e monitoramento aos municípios.

Este trabalho objetivou avaliar as condições higiênico sanitárias das Unidades de Alimentação e Nutrição de escolas públicas do estado do Tocantins.

\section{MATERIAL E MÉTODOS}

Este estudo é do tipo transversal de caráter descritivo e quantitativo desenvolvido pelo Centro Colaborador em Alimentação e Nutrição da Universidade Federal do Tocantins (CECANE/UFT) nas escolas públicas do estado do Tocantins.

Os municípios selecionados foram elencados pelo Fundo Nacional de Desenvolvimento da Educação (FNDE) para que o CECANE/UFT executasse assessoria e monitoramento, sendo um município da região norte $(8,3 \%)$, dois na região central $(16,6 \%)$ e os demais na região sudeste do Estado (75\%).

Os mesmos foram escolhidos obedecendo aos seguintes critérios: não cumprimento da determinação do artigo $14 \mathrm{da}$ Lei $11.947 / 2009$, que afirma que no mínimo $30,0 \%$ dos recursos financeiros repassados pelo FNDE, no âmbito do PNAE, deverão ser utilizados na aquisição de gêneros alimentícios da Agricultura Familiar, não prestação de contas (artigo 8 da Lei 11.947/2009), mais de
$30 \%$ de recurso do PNAE disponível na conta e denúncia formalizada junto à ouvidoria do FNDE oriunda dos órgãos de controle, como o Ministério Público, Tribunal de Contas da União e Controladoria Geral da União ${ }^{[9]}$.

Participaram da pesquisa duas nutricionistas Agentes do CECANE/UFT, que foram previamente capacitadas para a aplicação do formulário referente às Unidades de Alimentação e Nutrição escolares. Obteve-se, então, uma amostra de 12 municípios que resultaram em um total de 35 escolas públicas assessoradas.

Para a coleta dos dados utilizou-se um formulário semiestruturado encaminhado pelo FNDE com o objetivo de analisar as condições higiênico sanitárias das UAN escolares. Este formulário foi dividido em blocos contendo perguntas relativas a: A) Manipuladores B) Edifícios e instalações da área de preparo de alimentos C) Equipamentos e utensílios D) Higienização ambiental e saneamento E) Área de armazenamento (temperatura ambiente e temperatura controlada) F) Controle de qualidade e G) Controle de estoque.

As perguntas presentes no formulário estavam baseadas na legislação vigente de boas práticas de fabricação (RDC 216/2004) e assemelha-se à Lista de Verificação de Boas Práticas de Fabricação presente na RDC 275/2002, abordando apenas os requisitos pertinentes à produção da alimentação escolar $^{[3,4]}$.

A coleta de dados foi realizada pelas Agentes, que eram acompanhadas por representantes das escolas (diretores, coordenadores ou outros funcionários responsáveis pela alimentação escolar), encarregados de apresentar as UAN, manipuladores de alimentos e documentações solicitadas para comprovação das respostas. 
O período de coleta foi entre os meses letivos de maio a dezembro de 2016 e após a obtenção criou-se um banco de dados no programa Microsoft Excel versão 2010. Foram obtidos os percentuais relativos a cada pergunta do checklist com o objetivo de identificar as condições das UAN escolares avaliando as principais não conformidades.

\section{RESULTADOS E DISCUSSÃO}

\section{Manipuladores de alimentos}

A segurança da produção de alimentos depende dos manipuladores, que devem ser orientados a realizar as atividades de acordo com as boas práticas da RDC 216/2004.

Dentre os fatores que favorecem a segurança dos alimentos há a obrigatoriedade de realização de exames médicos pelos manipuladores, tanto admissionais, quanto periódicos $^{[3]}$.

Gráfico 1. Frequência de realização de exames laboratoriais pelos manipuladores das UAN escolares do Tocantins.

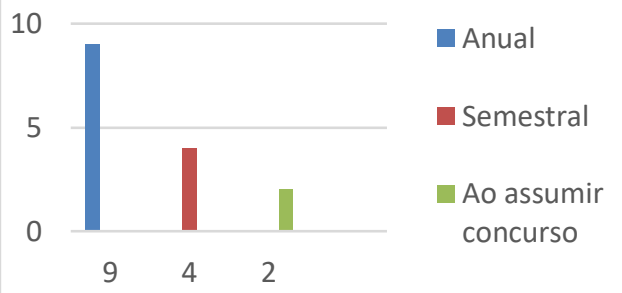

Fonte: Dados obtidos pelo CECANE/UFT. Tocantins. 2016.

Entre os resultados encontrados descritos no Gráfico 1 destaca-se a realização de exames há 10 anos atrás, fato que pode comprometer a saúde do trabalhador e dos escolares, que se tornam susceptíveis à doenças infectocontagiosas.
Tabela 1. Dados referentes aos manipuladores de alimentos.

\begin{tabular}{|l|l|l|}
\hline \multicolumn{2}{|l|}{ Variáveis } & N \\
\hline $\begin{array}{l}\text { Os manipuladores } \\
\text { médicos? }\end{array}$ & realizam exames \\
\hline Sim & 15 & 44,1 \\
\hline Não & 19 & 55,9 \\
\hline
\end{tabular}

Os manipuladores estavam devidamente uniformizados?

\begin{tabular}{|c|c|c|}
\hline Sim & 4 & 12,5 \\
\hline Não & 7 & 21,9 \\
\hline Parcialmente & 21 & 65,6 \\
\hline
\end{tabular}
adornos?

\begin{tabular}{|l|l|l|}
\hline Sim & 14 & 43,75 \\
\hline Não & 8 & 25 \\
\hline Parcialmente & 10 & 31,25 \\
\hline \multicolumn{2}{|l|}{ Os manipuladores recebem } & treinamento? \\
\hline Sim & 18 & 51,4 \\
\hline Não & 17 & 48,6 \\
\hline
\end{tabular}

Fonte: Dados obtidos pelo CECANE/UFT. Tocantins. 2016.

A não realização de exames periódicos e o não uso de equipamentos de proteção individuais (EPIs) e/ou uniformes também foram observadas por outros autores em escolas públicas brasileiras ${ }^{[10,6]}$.

De acordo com a RDC 216/2004, o manipulador deve utilizar uniformes limpos e touca, manter as mãos sempre limpas com as unhas aparadas e sem esmalte, bem como sem barba e/ou bigode ou qualquer tipo de adorno e com sapatos fechados ${ }^{[3]}$.

A baixa adesão do uso de uniformes e a contínua utilização de adornos durante o período de manipulação é apontado na literatura como consequência da falta de capacitação, de materiais disponíveis e má estrutura física para a adequada higienização das mãos e utilização dos EPIs, o que confere risco para a saúde dos escolares ${ }^{[2]}$.

Estudo similar ao desenvolvido pelo CECANE/UFT destaca o papel dos 
nutricionistas como treinador dos manipuladores, de forma a cumprir a função de responsável técnico do PNAE, sendo um dos profissionais que realizou treinamentos nas escolas do Tocantins (Gráfico 2) ${ }^{[11]}$.

Gráfico 2. Profissionais que ministraram os treinamentos para os manipuladores nas escolas do Tocantins.

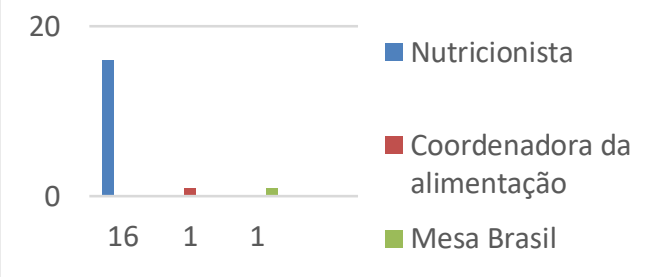

Fonte: Dados obtidos pelo CECANE/UFT. Tocantins. 2016.

De acordo com a resolução 465/2010 do Conselho Federal do Nutricionista, o mesmo possui papel fundamental dentro do PNAE, em que dentre suas atribuições complementares destaca-se a capacitações de atores envolvidos, como os manipuladores ${ }^{[12]}$.

Gráfico 3. Frequência de treinamento dos manipuladores das escolas do Tocantins.

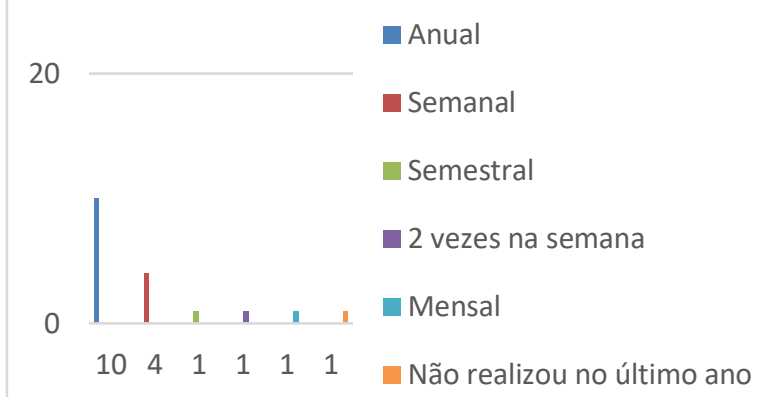

Fonte: Dados obtidos pelo CECANE/UFT. Tocantins. 2016.

Resultados sobre a frequência das capacitações (Gráfico 3) e sobre os principais temas abordados (Gráfico 4) foi comumente observado por outros autores que realizaram pesquisas referente ao assunto ${ }^{[13,14]}$.
Gráfico 4. Temas abordados nos treinamentos dos manipuladores das escolas do Tocantins.

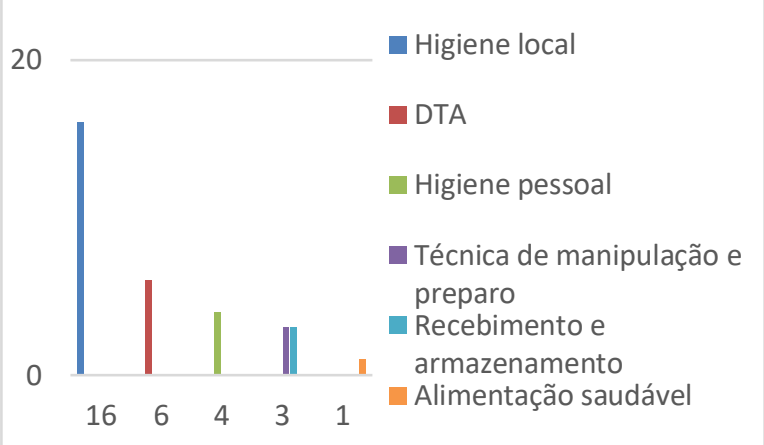

Fonte: Dados obtidos pelo CECANE/UFT. Tocantins. 2016.

A eficácia dos treinamentos realizados foi questionada por estudo que avaliou o perfil sócio educacional, o conhecimento e a percepção de manipuladores de alimentos em restaurantes comerciais, pontuando falhas nas metodologias empregadas, aplicação e frequência, que é tida como insuficiente ${ }^{[15]}$.

Além dos pontos citados, a intensa jornada de trabalho podem interferir na eficácia da produção ${ }^{[16]}$. Dessa forma, para a realização adequada do trabalho dos manipuladores é necessário que as escolas ofereçam condições de trabalho favorável, com todos os critérios avaliados acima, assim como instalações adequadas $^{[17]}$.

\section{Área de preparo dos alimentos}

As estruturas das UAN escolares devem estar conforme às premissas da RDC 216/2004, para evitar a proliferação de microrganismos nos alimentos e superfícies que entram em contato com os mesmos; e dispor de equipamentos e utensílios indispensáveis para a produção eficiente de refeições em condições nutricionais e microbiológicas satisfatórias ${ }^{[2]}$.

Porém, parte das escolas públicas, em especial no interior dos estados, foram adaptadas para a alimentação escolar, o que pode resultar em falhas no processo de 
produção, devido má condições físicas, funcionais e higiênicas.

$$
\text { Considerando a qualidade }
$$
microbiológica dos alimentos foi descrito na Tabela 2 dados sobre a infraestrutura das áreas de preparo visitadas pelo CECANE - UFT.

Tabela 2. Infraestrutura da área de preparo de alimentos das escolas do Tocantins.

\begin{tabular}{|c|c|c|}
\hline Variáveis & $\mathbf{N}$ & $\%$ \\
\hline \multicolumn{3}{|c|}{ O piso em bom estado de conservação? } \\
\hline Sim & 22 & 62,9 \\
\hline Não & 13 & 37,1 \\
\hline
\end{tabular}

As paredes e divisórias de acordo com a RDC 216?

\begin{tabular}{|c|c|c|}
\hline Sim & 24 & 68,6 \\
\hline Não & 9 & 25,7 \\
\hline Não se aplica & 2 & 5,7 \\
\hline \multicolumn{3}{|c|}{$\begin{array}{l}\text { O forro e teto em boas condições de } \\
\text { acordo com a RDC 216? }\end{array}$} \\
\hline Sim & 21 & 60 \\
\hline Não & 8 & 22,9 \\
\hline Não se aplica & 6 & 17,1 \\
\hline
\end{tabular}

\begin{tabular}{|l|l|l|}
\hline Sim & 0 & 0 \\
\hline Não & 12 & 34,3 \\
\hline Não se aplica & 23 & 65,7 \\
\hline
\end{tabular}

As lâmpadas com sistema de segurança contra quedas?

\begin{tabular}{|l|l|r|}
\hline Sim & 7 & 20 \\
\hline Não & 19 & 54,3 \\
\hline Não se aplica & 9 & 2,7 \\
\hline
\end{tabular}

Há presença de telas milimétricas nas janelas e portas?

\begin{tabular}{|l|l|r|} 
Sim (janelas) & 1 & 2,9 \\
\hline Não & 34 & 97,1 \\
\hline
\end{tabular}

As portas com proteção nas aberturas inferiores?

\begin{tabular}{|l|l|l|} 
Sim & 0 & 0 \\
\hline Não & 35 & 100
\end{tabular}

Fonte: Dados obtidos pelo CECANE/UFT. Tocantins. 2016.
Destaca-se que as estruturas das UAN devem impedir a entrada e o abrigo de insetos e outros animais, possuindo janelas com telas milimétricas e propiciar a ventilação adequada. A ausência de telas milimétricas foi observada em pesquisas semelhantes, corroborando com os resultados descritos ${ }^{[14}$, 19]. As legislações vigentes para UAN preconizam pelos materiais, estado de conservação e higienização, com piso, paredes, portas e teto de material liso, resistente, impermeável, lavável, de cores claras, sem propiciar o acúmulo de alimentos ou sujidades, em que os ralos devem possuir inclinação adequada e sistema de fechamento.

Frisa-se que as edificações devem estar isentas de goteiras, vazamentos, umidade, trincas, rachaduras, bolor e descascamento ${ }^{[16]}$. A infraestrutura deve conter iluminação adequada, com proteção contra quebras das lâmpadas para evitar a eventualidade de contaminação dos alimentos com materiais físicos (como fragmentos de vidro) e acidentes [21].

Além das incongruidades relatadas na aplicação de checklist (Tabela 2) foi constatada quanto à área de preparo dos alimentos a não presença de forro ou forro sujo, de isopor ou mofado; materiais de madeiras, como prateleiras e armários e teto; paredes apenas rebocadas e chão sem piso de cerâmica, de terra batida, com cores diversas (vermelha, amarela); e ralos improvisados com canos.

Foi encontrado também ventiladores sujos ligados na área de preparação, cozinhas com pias do lado de fora da área de manipulação, bem como botijões de gás dentro das cozinhas e cortinas de pano. Todos esses fatores contribuem para maiores riscos de contaminação ou riscos para os manipuladores de alimentos. 


\section{Equipamentos e Utensílios}

A produção eficiente de alimentos é dependente de todos os critérios abordados nas outras secções e da presença de equipamentos e utensílios adequados, entretanto foi constatado a ausência de geladeiras e fornos nas visitas realizadas pelo CECANE/UFT.

A Tabela 3 apresenta os dados referentes aos equipamentos e utensílios observados nas unidades de alimentação e nutrição escolares.

Tabela 3. Equipamentos e Utensílios das UAN escolares do Tocantins.

\begin{tabular}{|l|l|l|}
\hline $\begin{array}{l}\text { Variáveis } \\
\text { A cozinha possui todos }\end{array}$ \\
\begin{tabular}{|l|l|} 
necessários? \\
Sim
\end{tabular} & 25 & 71,4 \\
\hline Não & 10 & 28,6 \\
\hline
\end{tabular}

Há equipamentos para armazenamento em temperatura controlada?

\begin{tabular}{l|l|r|}
\hline Sim & 34 & 97,1 \\
\hline Não & 1 & 2,9
\end{tabular}

Fonte: Dados obtidos pelo CECANE/UFT. Tocantins. 2016.

A presença de balcões que mantem a temperatura adequada das refeições é um dos equipamentos chaves para a produção de qualidade nas UAN, porém a presença de balcões não foi observada em nenhuma escola pública visitada pelas agentes do CECANE UFT em 2016.

\section{Higienização ambiental e saneamento}

O cuidado com a higienização do ambiente e saneamento é chave para o processo de produção de alimentos seguros, sendo apresentados os dados encontrados nesse bloco de avaliação na tabela 4 .
Tabela 4. Higienização ambiental e saneamento nas escolas do Tocantins.

\begin{tabular}{|c|c|c|}
\hline Variáveis & $\mathbf{N}$ & $\%$ \\
\hline \multicolumn{3}{|c|}{ Lixo armazenado de modo adequado? } \\
\hline Sim & 14 & 40 \\
\hline Não & 21 & 60 \\
\hline \multicolumn{3}{|c|}{ Existem evidência de roedores? } \\
\hline Sim & 2 & 5,7 \\
\hline Não & 33 & 94,3 \\
\hline \multicolumn{3}{|c|}{$\begin{array}{l}\text { UAN limpa, organizada, sem restos de } \\
\text { alimentos, lixos, objetos em desuso e } \\
\text { estranhos ao local e sem indícios de } \\
\text { presença de animais? }\end{array}$} \\
\hline Sim & 32 & 91,4 \\
\hline Não & 3 & 8,6 \\
\hline \multicolumn{3}{|c|}{ Existe reservatório de água? } \\
\hline Sim & 33 & 94,3 \\
\hline Não & 2 & 5,7 \\
\hline \multicolumn{3}{|c|}{$\begin{array}{l}\text { Ocorre higienização dos reservatórios a } \\
\text { cada } 6 \text { meses? }\end{array}$} \\
\hline Sim & 17 & 51,5 \\
\hline Não & 16 & 48,5 \\
\hline \multicolumn{3}{|c|}{ Existe sistema de filtragem? } \\
\hline Sim & 11 & 31,4 \\
\hline Não & 24 & 68,6 \\
\hline
\end{tabular}

Fonte: Dados obtidos pelo CECANE/UFT. Tocantins. 2016.

Em virtude das características parecidas das cozinhas domésticas e escolares é comum a presença de lixeiras dentro da área de manuseio dos alimentos, lixeiras abertas, com necessidade de contato manual ou mesmo próximo ao local de depósito ou descarga de alimentos, bem como objetos em desuso na área de manipulação.

Essas não conformidades poluem o ambiente, aumentam as chances de proliferação de pragas e vetores, e podem afetar a saúde de crianças e trabalhadores do local ${ }^{[6]}$, sendo descrito em outros estudos resultados conforme os apresentados na Tabela $4^{[14,6]}$. Ressalva-se ainda que encontrou-se indícios de roedores em duas UAN escolares do Tocantins. 
Nas escolas deve-se ter o cuidado quanto ao fornecimento de água, devido ser fator imprescindível na produção de alimentos e que determina a inocuidade dos mesmos ${ }^{[6]}$. Os locais de armazenamento de água devem ser higienizados a cada seis meses no máximo ${ }^{[3]} \mathrm{e}$ devem ser livres de rachaduras, vazamentos, infiltrações, descascamentos e outros defeitos.

Destaca-se que nas escolas que havia o sistema de filtragem, a mesma era feita, em sua maioria, em bebedouros, que possuíam filtros de carvão ou de barro. Encontrou-se estudo com resultados superiores quanto à higienização periódica dos reservatórios, com a devida documentação para comprovação da ação ${ }^{[22]}$.

A discrepância entre resultados do presente estudo e da literatura ressaltam a necessidade de maiores investimentos e fiscalização para que a legislação seja executada, com análise da qualidade da água fornecida aos estudantes.

\section{Área de armazenamento}

O armazenamento adequado dos alimentos garante a qualidade do produto, tanto física, química e biológica, sendo essencial no processo de produção de alimentos seguros. Assim, na tabela 5 há a descrição dos principais resultados encontrados acerca do armazenamento de alimentos nas escolas visitadas.
Tabela 5. Armazenamento dos alimentos nas escolas do Tocantins.

\begin{tabular}{|c|c|c|}
\hline Variáveis & \multicolumn{2}{|r|}{$\%$} \\
\hline \multicolumn{3}{|c|}{$\begin{array}{l}\text { sao guaraados } \\
\text { alimentícios? }\end{array}$} \\
\hline Depósitos & 31 & 88,6 \\
\hline Armários & 4 & 11,4 \\
\hline \multicolumn{3}{|c|}{ A área de armazenamento é arejada? } \\
\hline Sim & 16 & 45,7 \\
\hline Não & 19 & 54,3 \\
\hline \multicolumn{3}{|c|}{ Há estrados fixos ou móveis? } \\
\hline Sim & 5 & 14,3 \\
\hline Não & 26 & 74,3 \\
\hline Não se aplica & 4 & 11,4 \\
\hline \multicolumn{3}{|c|}{$\begin{array}{l}\text { Há circulação de ar entre pilhas de } \\
\text { alimentos? }\end{array}$} \\
\hline Sim & 21 & 60 \\
\hline Não & 7 & 20 \\
\hline Parcialmente & 7 & 20 \\
\hline \multicolumn{3}{|c|}{ As prateleiras são laváveis? } \\
\hline Sim & 18 & 51,4 \\
\hline Não & 17 & 48,6 \\
\hline \multicolumn{3}{|c|}{$\begin{array}{l}\text { Os alimentos são retirados de caixas de } \\
\text { papelão ou madeira após recebimento? }\end{array}$} \\
\hline Sim & 24 & 68,3 \\
\hline Não & 6 & 17,1 \\
\hline Parcialmente & 5 & 14,3 \\
\hline
\end{tabular}

Fonte: Dados obtidos pelo CECANE/UFT. Tocantins. 2016.

Sabe-se que a estocagem de alimentos perecíveis em prateleiras ou estrados deve ocorrer, de maneira a manter os alimentos afastados da parede, solo e/ou teto, de forma a prevenir o acesso de insetos e alterações da umidade ${ }^{[6]}$.

Entretanto, nas visitas realizadas nas unidades escolares tocantinenses foi notado outras contrariedades, como janelas abertas dos depósitos, bem como depósitos adaptados, com alimentos sem a organização em pilhas e/ou empilhados no meio da cozinha (em caixas, fora de armários), prateleiras de madeiras forradas com tecido e utensílios em desuso armazenados juntos aos alimentos. 
O armazenamento dos alimentos em temperatura controlada é de grande valia, visto que, propicia o uso dos alimentos por um período maior de tempo, devido o controle do crescimento microbiológico e maior conservação do estado dos alimentos ${ }^{[6]}$.

No Gráfico 5 estão descritos os equipamentos que possibilitam o controle térmico encontrados nas escolas tocantinenses.

Gráfico 5. Equipamentos de refrigeração encontrados nas escolas tocantinenses.

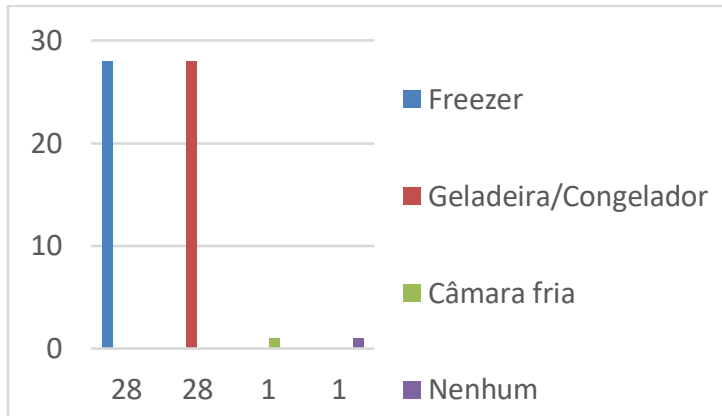

Fonte: Dados obtidos pelo CECANE/UFT. Tocantins. 2016.

A ausência de equipamentos de refrigeração também foi identificada em outro estudo em escolas rurais da região centro -oeste [20], corroborando com dado apresentado no Gráfico 5. Foi constatado que em $20 \%$ das escolas visitadas a quantidade de equipamentos de refrigeração não supriam a demanda da escola e que $5,7 \%$ dos equipamentos presentes não se apresentavam em bom estado de funcionamento e higiene.

Observou-se o acúmulo de gelo nos equipamentos de refrigeração em 42,9\% das escolas, seja totalmente ou parcialmente. Ressalva-se que após o descongelamento a taxa de multiplicação de microrganismos é semelhante à do alimento fresco, podendo ocasionar, diante do contínuo crescimento, eventos de DTA ${ }^{[17]}$.

\section{Controle de qualidade}

As escolas visitadas também foram avaliadas quanto ao controle de qualidade dos alimentos, com dados expostos na Tabela 6. Este controle deve ser realizado em todas as etapas, desde o recebimento, armazenamento, retirada e a produção de alimentos.

Tabela 6. Controle de qualidade nas escolas do Tocantins.

\begin{tabular}{|c|c|c|}
\hline \multicolumn{2}{|c|}{ Variáveis } & $\%$ \\
\hline \multicolumn{3}{|c|}{$\begin{array}{l}\text { Gêneros abertos refrigerados } \\
\text { rotulados de acordo com a legislação? }\end{array}$} \\
\hline Sim & 5 & 14,3 \\
\hline Não & 30 & 85,7 \\
\hline \multicolumn{3}{|c|}{$\begin{array}{l}\text { Os alimentos armazenados } \\
\text { devidamente etiquetados com data? }\end{array}$} \\
\hline Sim & 5 & 14,3 \\
\hline Não & 30 & 85,7 \\
\hline \multicolumn{3}{|c|}{$\begin{array}{l}\text { No recebimentos dos alimentos } \\
\text { verificadas características sensoriais? }\end{array}$} \\
\hline Sim & 35 & 100 \\
\hline Não & 0 & 0 \\
\hline
\end{tabular}

Fonte: Dados obtidos pelo CECANE/UFT. Tocantins. 2016.

A infraestrutura e existência de utensílios, como termômetros e balanças interferem diretamente no controle de qualidade $^{[6]}$. O não registro do prazo de validade dos alimentos após abertos também foi apresentado em outro estudo ${ }^{[6]}$.

As falhas nas ações de controle de qualidade no armazenamento demonstram a necessidade de organização das unidades de alimentação escolares, bem como capacitação dos responsáveis por realizar esse controle, diante dos riscos de contaminação e DTA, além das possíveis perdas nutricionais, sensoriais e desperdícios dos alimentos pelo mau estado de conservação $^{[6]}$. 
O controle de gêneros, tanto acerca da qualidade quanto quantidade, é de grande valia para evitar os desperdícios de alimentos e necessário para que produtos em maus estado de conservação sejam jogados fora.

Em prova da não efetiva realização do controle de gêneros foram identificados, nas visitas feitas pelo CECANE /UFT, 6 escolas com produtos fora da validade, que eram leite pasteurizado, pães e flocos de milho.

\section{Controle de estoque}

A resolução número 26 que dispõe sobre o atendimento da alimentação escolar prevê que o Estado, Município e Distrito Federal deverão assegurar a estrutura necessária para o controle de estoque e armazenamento de gêneros alimentícios ${ }^{[23]}$.

O texto é complementado pela Nota Técnica $\mathrm{n}^{\circ} 5002^{[24]}$, que apresenta critérios necessários para o controle de estoque, como registros, para planejamento e acompanhamento do fluxo de recebimento e saídas.

Nas escolas visitadas pelo CECANE/UFT o controle de estoque é realizado em todas as escolas, obedecendo a retirada de alimentos do estoque de acordo com o sistema "primeiro que entra é o primeiro que sai" ou "primeiro que vence é o primeiro que sai", além de serem verificadas as características sensoriais dos produtos no recebimento.

Contudo, em 8 escolas não é realizado controle quantitativo dos gêneros alimentícios que são recebidos no estoque e retirados para o preparo da alimentação. Observou-se que a periodicidade de estabelecimento das informações do controle de gêneros variavam entre as escolas, como é apresentado no Gráfico 6.
Gráfico 6. Periodicidade da consolidação das informações de controle de gêneros alimentícios.

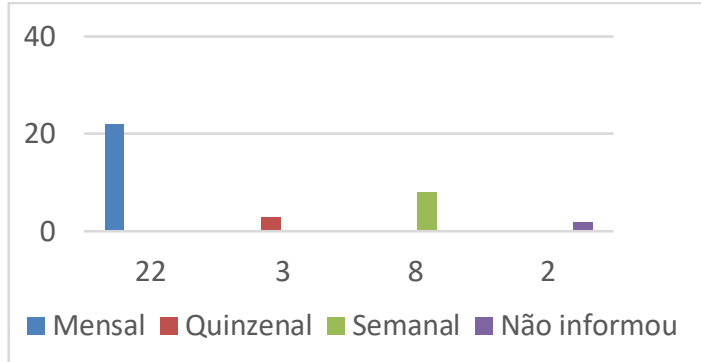

Fonte: Dados obtidos pelo CECANE/UFT. Tocantins. 2016.

Destaca-se o papel de gestores municipais, estaduais e das escolas gerenciar os recursos financeiros para a resolução de demanda quanto à infraestrutura: presença de materiais de madeira (armários para depósitos e forros dos tetos), chão de terra batida, paredes rebocadas, falta de telas milimétricas, bem como falta de equipamentos, como fornos, geladeiras e uniformização de manipuladores.

Compreende-se que problemas quanto à infraestrutura interferem nas condições higiênicas das UAN, assim como a falta de treinamento para os manipuladores que propicia a má higienização de alimentos, equipamentos, utensílios e ambiente.

Além da falha no processo de higienização, outras adversidades foram constatadas nas visitas in loco às escolas, como presença de caixas de papelão ou madeira nas UAN, não rotulagem ou etiquetação de gêneros alimentícios, produtos fora da validade nos depósitos e indícios de roedores.

A realização de treinamentos intermunicipais para manipuladores é uma das ações que podem ser organizadas, com parceria entre estado, município e o CECANE /UFT, com a seleção de cidades polos e convite para municípios vizinhos participarem das capacitações e atualizações. 
Entretanto, as capacitações intermunicipais não excluiriam a necessidade de capacitação frequente em cada escola, de acordo com a demanda, feita por nutricionista ou profissional capacitado para a realização dessas ações.

Assim como a capacitação de outros atores do Programa faz-se necessário, o que abrange prefeitos, secretários de educação e agricultura, coordenadores da alimentação escolar, setores financeiros e de compras.

\section{CONCLUSÃO}

As escolas públicas municipais e estaduais do estado do Tocantins apresentaram condições higiênico sanitárias deficientes, em que não são atendidas as disposições descritas na RDC 216/2004 com base nos manipuladores de alimentos, área de preparo dos alimentos, equipamentos e utensílios, higienização ambiental e saneamento, armazenamento dos alimentos, controle de qualidade e controle de estoque.

A capacitação dos manipuladores de alimentos deve ser vista como uma ação permanente no ambiente escolar, contribuindo para a produção de alimentos seguros. Os resultados apontam a necessidade de intervenções por parte dos gestores com o objetivo de viabilizar a oferta de uma alimentação segura para os discentes.

\section{REFERÊNCIAS}

[1] Oliveira IG. Alimentação Escolar no discurso de manipuladores de alimentos de escolas brasileiras. [Dissertação]. Goiânia: Universidade Federal de Goiás; 2017. 89p.

[2] Rezer DS. Alimentação escolar: Recursos humanos e equipamentos em escolas públicas de Porto Alegre/RS [monografia]. Porto
Alegre: Universidade Federal do Rio Grande do Sul; 2015. 38p.

[3] Brasil. Ministério da Saúde. Agência Nacional de Vigilância Sanitária. Resolução da Diretoria Colegiada no 216 de 15 de setembro de 2004. Dispõe do Regulamento Técnico de Boas Práticas para Serviços de Alimentação. Diário Oficial [da República Federativa do Brasil], Brasília, 15 de set. 2004.

[4] Brasil. Ministério da Saúde. Agência Nacional de Vigilância Sanitária. Resolução $n^{\circ}$ 275 de 21 de outubro de 2002. Dispõe sobre o Regulamento Técnico de Procedimentos Operacionais Padronizados aplicados aos Estabelecimentos

Produtores/Industrializadores de alimentos e Lista de verificação das Boas Práticas de Fabricação em Estabelecimentos Produtores/Industrializadores de Alimentos. Diário Oficial [da República Federativa do Brasil], Brasilia, 23 de outubro de 2003.

[5] Ferreira MA, São José JFB, Tomazini APB, Martini HSD, Milagres RCM, PinheiroSant'Ana HM. Avaliação da adequação às boas práticas em unidades de alimentação e nutrição. Revista Instituto Adolfo Lutz. São Paulo. 2011; 70(2):230-235. Disponível em: http://periodicos.ses.sp.bvs.br/pdf/rial/v70n2 /v70n2a20.pdf.

[6] Cardoso RCV, Góes JAW, Almeida RCC, Guimarães AG, Barreto DL, Silva AS e et al. Programa nacional de alimentação escolar: há segurança na produção de alimentos em escolas de Salvador (Bahia)? Rev. Nutri. Campinas.2010; 23(5): 801-811.

[7] Stedefeldt E, Cunha DT, Silva JÊEA, Silva SM, Oliveira ABA. Instrumento de avaliação das Boas Práticas em Unidades de Alimentação e Nutrição Escolar: da concepção à validação. Revista Ciência saúde coletiva. 2013; 18(4):947953. Disponível em: 
http:/ /www.scielo.br/scielo.php?script=sci_art text\&pid=S1413-81232013000400006\&lng=en.

[8] WHO. World Health Organization. WHO campaigns - World Health Day 2015: Foodsafety<http://www.who.int/campaigns/ world-health-day/2015/event/en/.Acesso em 22 de junho de 2017.

[9] Brasil. Lei no 11.947, de 16 de junho de 2009. Dispõe sobre o atendimento da alimentação escolar e do Programa Dinheiro Direto na Escola aos alunos da educação básica e dá outras providências. Diário Oficial [da República Federativa do Brasil], Brasília, 17 jun. 2009.

[10] Campos AKC. Avaliação das condições higiênico-sanitárias de manipuladores de alimentos e utensílios de mesa de escolas públicas municipais de Natal, RN [dissertação]. Natal: Universidade Federal do Rio Grande do Norte; 2009. 50 p.

[11] Oliveira ABA. Condição higiênico-sanitária da água, alimentos e ambiente de preparo da alimentação em escolas públicas atendidas pelo Programa Nacional de Alimentação Escolar no Município de Porto Alegre [tese]. Porto Alegre: Universidade Federal do Rio Grande do Sul; 2011. 168 p. Disponível em:http://www.scielo.br/scielo.php?script=sci _arttext\&pid=S1415-

$52732010000500010 \& \operatorname{lng}=$ en\&nrm $=$ isso.

[12] Brasil. Conselho Federal de Nutricionistas. Resolução/CFN número 465, de 23 de agosto de 2010. Dispõe sobre as atribuições do Nutricionista, estabelece parâmetros numéricos mínimos de referência no âmbito do Programa de Alimentação Escolar e dá outras providências. Diário Oficial [da República Federativa do Brasil], Brasília, 16 jun. 2010.

[13] Souza AA, Bezerra OMPA, Bonomo E, Silva CAM. Atuação de nutricionistas responsáveis técnicos pela alimentação escolar de municípios de Minas Gerais e Espírito Santo. Ciência \& Saúde Coletiva. Rio de Janeiro. 2017, 22(2):593-606. Disponível em: http://www.scielo.br/scielo.php?script=sci_art text\&pid $=$ S1413 -

$81232017000200593 \& \operatorname{lng}=$ en\&nrm $=$ iso\&tlng= $\mathrm{pt}$

[14] Almeida KM, Andre MCP, Campos MRH, Diaz MEP. Condições físicos, funcionais e higiênicas sanitárias das unidades de alimentação e nutrição de escolas da Região Centro-oeste, Brasil. Revista de Nutrição. Campinas. 2014; 27(3): 343-356. Disponível em: http:/ / www.scielo.br/scielo.php?pid=S1415$52732014000300343 \&$ script $=$ sci_abstract\&tlng $=\mathrm{pt}$

[15] Gonzalez CD, Perrella NG, Rodrigues RL, Gollücke APB; Schattan RB, Toledo LP. Conhecimento e percepção de risco sobre higiene alimentar em manipuladores de alimentos de restaurantes comerciais. Revista de Nutrição. São Paulo.2009; 34(3): 45- 56. Disponível http:// files.bvs.br/upload/S/15198928/2009/v34n3/a004.pdf

[16] Fernandes AGS, Fonseca ABC, Silva AA. Alimentação Escolar como espaço para educação em saúde: percepção das merendeiras do município do Rio de Janeiro, Brasil. Revista Ciências da Saúde Coletiva. Rio de Janeiro. 2014; 19(1):39-48. Disponível em: http://www.scielo.br/scielo.php?script=sci_art text\&pid $=$ S1413 $81232014000100039 \& \operatorname{lng}=$ en\&nrm=iso\&tlng= pt.

[17] Gomes NAAA, Campos MRH, Monego ET. Aspectos higiênico-sanitários no processo produtivo dos alimentos em escolas públicas do Estado de Goiás, Brasil. Revista de Nutrição. Campinas. 2012; 25(4):473-485. Disponível em: http:/ /www.scielo.br/scielo.php?script=sci_art text\&pid=S1415-52732012000400005. 
[18] Beux J, Primon V, Busato MA. Condições higiênico - sanitárias em local de produção e distribuição de alimentos em escolas públicas sob a ótica da produção mais limpo. Revista da UNIFEBE. 2013; 1(11); 1-13. Disponível em: http://periodicos.unifebe.edu.br/index.php/re vistaeletronicadaunifebe/article/view/148/78.

[19] Cunha DT, Stedefeldt E, Rosso VV. Boas práticas e qualidade microbiológica nos serviços de alimentação escolar: uma revisão sistemática. Revista Brasileira Pesquisa Saúde. 2012; 14(4):108-121. Disponível em: http://periodicos.ufes.br/RBPS/article/view/5 $127 / 3853$.

[20] Almeida KM. Condições físico-funcionais e higienicossanitárias das unidades de alimentação e nutrição de escolas da região centro-oeste, Brasil [dissertação]. Goiânia: Universidade Federal do Goiás; 2013, 98p.

[21] Hilário MBM, Leite M. Condições higiênico-sanitárias do serviço de alimentação, de duas escolas, do município de porto velho RO [monografia]. Porto Velho: Faculdade São Lucas; 2015, 33p.

[22] Cardoso RCV, Almeida RCC, Guimarães AG, Góes JAW, Santana AAC, Silva AS e et al.Qualidade da água utilizada em escolas atendidas pelo Programa Nacional de Alimentação Escolar (PNAE), em Salvador-BA. Revista Instituto Adolfo Lutz. São Paulo. 2007, 66(3):287-291. Disponível em:http://periodicos.ses.sp.bvs.br/scielo.php?s cript $=$ sci_arttext\&pid $=$ S0073

98552007000300012\&lng=pt.

[23] Brasil. Ministério da Educação. Fundo Nacional de Desenvolvimento da Educação. Resolução número 26, de 17 de junho de 2013. Dispõe sobre o atendimento da alimentação escolar aos alunos da educação básica no âmbito do programa nacional de alimentação escolar - PNAE. Diário Oficial [da República Federativa do Brasil], Brasília, 18 de jun. 2013.
[24] Brasil. Ministério da Educação. Fundo Nacional do Desenvolvimento da Educação. Nota Técnica 5002/2016/COSAN/CGPAE/DIRAE. Dispõe sobre controle de estoque de alimentos no PNAE. 